\title{
Increased Spontaneous Unit Activity and Appearance of Spontaneous Negative Potentials in the Goldfish Tectum during Refinement of the Optic Projection
}

\author{
Bradley J. Kolls and Ronald L. Meyer \\ Department of Developmental and Cell Biology, University of California, Irvine, Biological Sciences II Building, Irvine, \\ California 92697
}

\begin{abstract}
Spontaneous (not retinally driven) postsynaptic activity was examined during activity-dependent refinement of optic fibers in the goldfish tectum. Unit recordings in vivo and in vitro demonstrated that spontaneous tectal activity increased to $150 \%$ of normal during refinement at 1-2 months after optic nerve crush and subsequently returned to baseline over the next month. This increase was not mimicked by long-term denervation indicating an effect specifically influenced by regenerating fibers. Loss of optic input was also found to induce spontaneous negative potentials (SNPs) rapidly in the tectum. SNPs were negative, monophasic potentials of $70-120 \mathrm{msec}$ duration and -0.15 to $-1.5 \mathrm{mV}$ amplitude. SNPs occurred with no apparent periodicity at a frequency of $\sim 0.3-0.6 \mathrm{~Hz}$. Multiple electrode recordings and depth analysis showed that SNPs were localized events occurring in columnar domains of tectum a few hundred micrometers wide. Cross-correlation analysis
\end{abstract}

revealed that SNPs were strongly correlated with local unit bursting, suggesting SNPs are generated by the summed synaptic and spike currents of coactive cells in small regions of the tectum. SNPs were suppressed by a low concentration of APV indicating they were regulated by NMDA receptors. During regeneration, the number and size of SNPs reached a peak during refinement and subsequently decreased, eventually disappearing. This temporal association with refinement suggests that these patterns of postsynaptic activity may have functional relevance. It is hypothesized that SNPs or the underlying activity that produces them increases the excitability of target cells, allowing the weak, less-convergent input from regenerating axons to drive target groups of cells in the tectum during refinement.

Key words: goldfish; retinotectal system; tectum; spontaneous activity; regeneration; visual system; postsynaptic activity
The formation of connections in the visual system has been intensely studied as a model for the formation of ordered connections. One of the major findings to emerge from these studies is that impulse activity plays a critical role in generating order. Although some of this activity is derived from visual stimulation, many of the organizational features of the visual system can be generated by spontaneous activity in the absence of visual experience. These features include retinotopic order in the retinotectal projection of lower vertebrates, the laminar innervation of dorsal lateral geniculate, center-surround properties of geniculate neurons, ocular dominance columns in mammalian visual cortex, eye-specific segregation in the dually innervated tectum of frogs and fish, and a number of response properties of neurons in the visual cortex (Schmidt and Tieman, 1985; Shatz, 1990, 1994; Katz and Shatz, 1996).

Locally correlated spontaneous activity in the retina has long been thought to drive activity-dependent ordering in the visual system according to the following rule: fibers that fire together terminate together (Meyer, 1982). Early electrophysiological recordings on the retina of adult cats, rabbits, and goldfish found that retinal ganglion cells exhibited maintained activity in the

Received June 21, 1999; revised Sept. 20, 1999; accepted Sept. 28, 1999.

This work was supported by National Institutes of Health Grant EY6746 to R.L.M. and the University of California, Irvine, Medical Scientist Training Program to B.J.K.

Correspondence should be addressed to Dr. Ronald L. Meyer, Department of Developmental and Cell Biology, University of California, Irvine, Biological Sciences II Building, Irvine, CA 92697. E-mail: rlmeyer@uci.edu.

Copyright (C) 1999 Society for Neuroscience $0270-6474 / 99 / 190338-13 \$ 15.00 / 0$ dark and this activity was correlated between neighboring cells (Arnett, 1978; Arnett and Spraker, 1981; Mastronarde, 1983). More recent studies on developing mammals found that activity in optic fibers was highly episodic occurring in intermittent bursts (Maffei and Galli-Resta, 1990), and subsequent recordings using multielectrode arrays revealed waves of retinal ganglion cell activity that were propagated across the retina (Meister et al., 1991; Wong et al., 1993). Similar waves of activity have been observed in the developing retina of turtles (Sernagor and Grzywacz, 1995). These observations suggest that there are developmentally regulated patterns of intense locally correlated activity that may serve to drive activity-dependent ordering.

The possibility that there may be special patterns of spontaneous (nonoptic-driven) activity in the target neurons during activity-mediated ordering in the visual system has received little attention. Intrinsic postsynaptic activity could serve a number of important functions. It could lower the threshold for activation by optic fibers to permit the operation of Hebbian mechanisms mediating synaptic stabilization. If this spontaneous target activity were locally correlated, it could also serve to define domains of cells as targets for activity-dependent termination. To investigate this, we recorded the spontaneous activity of tectal neurons in adult goldfish during the period in which regenerating optic fibers undergo activity-dependent refinement. Spontaneous (nonopticdriven) activity was monitored by acutely silencing optic fibers in the retina with tetrodotoxin. We found that local regions of tectum exhibited periodic spontaneous negative potentials (SNPs) of more than a millivolt during refinement. These were not observed in normal fish. Concurrent with each SNP was 
intense bursting activity in tectal neurons at the site of the SNP. This activity did not appear to be propagated across the tectum as waves but, instead, defined local domains of episodic spontaneous activity. These results raise the possibility that patterned, spontaneous postsynaptic activity may play a role in activitydependent refinement of the visual system.

\section{MATERIALS AND METHODS}

Animals and optic nerve crush surgery. All animals were adult goldfish, Carassius auratus, $5-15 \mathrm{~cm}$ in length. The fish were housed in standard glass aquariums at $20-22^{\circ} \mathrm{C}$ on a $12 \mathrm{hr}$ light/dark cycle. All surgical procedures were performed on fish anesthetized with tricaine methanesulfonate (A-5040; Sigma, St. Louis, MO) using a dissecting microscope and sterile instruments. The right optic nerve was crushed in the orbit $\sim 1$ $\mathrm{mm}$ behind the eye by repeated compression with fine forceps. The fish were then returned to their tank, and regeneration was allowed to take place for a variable amount of time. In some cases the entire eye was removed, and the fish were returned to their tanks for a minimum of $12 \mathrm{~d}$ before recording from the denervated tecta.

Intraocular tetrodotoxin injections. Injections of tetrodotoxin (TTX) were generally done $12-24 \mathrm{hr}$ before recording. The fish were anesthetized with tricaine methanesulfonate, and a small hole was made in the dorsal surface of the eye on or near the limbus with a sterile 26 gauge needle. A Hamilton syringe equipped with a glass pipette tip $\sim 10-20 \mu \mathrm{m}$ across was inserted through the hole, and $0.05 \mu \mathrm{l}$ of $1.2 \mathrm{~mm}$ TTX in 50 $\mathrm{mm}$ citrate buffer was injected into the vitreous. Typically both eyes received an injection. The fish were then revived and placed back in their tank until the time of recording. TTX-injected fish were always tested for the presence of visually evoked responses using light flash or large moving visual stimuli both before and after each experiment to ensure that action potential activity from the retina was blocked during recording. In some experiments, TTX was injected during the experiment after recording a 30-60 min pre-TTX period. The injection needle was placed in a micromanipulator, and TTX was injected while the fish was in the in vivo setup. Under these conditions, effects on unit activity occurred in $<10 \mathrm{~min}$ after the injection, and complete blockade of visual and light responses occurred within 15-20 min.

The in vivo preparation. This preparation has been described in detail elsewhere (Meyer and Brink, 1988; Lyckman and Meyer, 1995). Briefly, fish were anesthetized in Finquel and injected intramuscularly with curare at $2 \mu \mathrm{g} / \mathrm{gm}$. A window was then cut in the skull overlying the tecta allowing access for recording. Fatty tissue and pia were carefully dissected away to provide better drug penetration. The fish was then placed in a Plexiglas holder, and water was continuously passed over the gills via a recirculating pump. A steady flow $(0.5-1 \mathrm{ml} / \mathrm{min})$ of balanced salt solution (BSS; $120 \mathrm{~mm} \mathrm{NaCl}, 10 \mathrm{~mm}$ HEPES, $1.5 \mathrm{~mm} \mathrm{KCl}, 1.5 \mathrm{~mm}$ $\mathrm{CaCl}_{2}, 3.0 \mathrm{~mm} \mathrm{MgCl}_{2}$, and $0.5 \mathrm{mM} \mathrm{Na}_{2} \mathrm{SO}_{4}$ ) was started over the tecta, and recording electrodes were then placed in the tecta. Recording began 15-20 min after the fish was placed in the setup, thus allowing the anesthetic to clear and reduce the variations in activity levels caused by anesthesia. Stable recordings could be routinely made from this preparation for $>6 \mathrm{hr}$.

The in vitro isolated tectum preparation. Fish were anesthetized in tricaine methanesulfonate. The brain case with eyes was separated by a pair of lateral incisions through the mouth back to the gills and a dorsoventral incision behind the cerebellum. The brain case was placed in ice-cold BSS under a stereomicroscope. The brain together with optic nerves was removed by a series of incisions with fine iridectomy scissors through the ventral surface and by incisions through the optic nerves immediately behind the eye. The ventral cranium was then dissected away, and the optic nerves were uncrossed by cutting the connective tissue carefully at the chiasm. Each optic tectum was then cut from surrounding brain such that the optic pathway and entire optic nerve were preserved. The tecta were transferred to a fresh dish of BSS and placed at $4^{\circ} \mathrm{C}$ for $45-60 \mathrm{~min}$. The preparation was then moved to room temperature $\left(22-27^{\circ} \mathrm{C}\right)$ for $10 \mathrm{~min}$ and finally placed in a modified interface-recording chamber similar to the preparation used in previous studies (van Deusen and Meyer, 1990). The modification consisted of placing a second net over the top of the first net with the tissue held between. This arrangement allowed the tecta to be submerged, thereby providing superior drug access. This preparation was found to be longer lived and to exhibit greater stability, with no episodes of spreading depression like those reported for the standard interface chamber (Teyler et al., 1981; Langdon and Freeman, 1987; van Deusen and Meyer,
1990). A gas mixture containing $95 \%$ oxygen and $5 \%$ carbon dioxide was bubbled through room temperature BSS that was continuously perfused through the chamber for the duration of the experiment at a rate of $\sim 2$ $\mathrm{ml} / \mathrm{min}$.

Focal photostimulation. Light flashes were used as a physiological stimulus. The light source was a strobe light (Grass model PS2 photostimulator) set on the highest intensity, 16. The circular strobe was covered with a diffuser and masked to create a 1 inch, square stimulus. Typically two electrodes were placed in one tectum to record SN Ps. The stimulus was positioned so that only one electrode responded to the stimulus allowing the second electrode to act as a control for global changes in SNP rate and general health and stability of the preparation. A drop of oil was placed on the cornea to prevent drying, and then the visual field for the stimulated electrode was determined by manually moving a small spot in front of the eye. The square stimulus was then placed in the center of the visual field 12-18 inches from the front of the eye. Light flashes were triggered by computer at frequencies of $0.2,0.5$, and $1.0 \mathrm{~Hz}$.

Recording. Recordings were made using platinum-plated tungsten electrodes. The electrodes were encased in glass with exposed, sharp, tapered tips $10-80 \mu \mathrm{m}$ in length. These electrodes were able to record spontaneous multiunit and spontaneous field potential data simultaneously. In most experiments, impulse activity in optic fibers was eliminated surgically or by injecting TTX intraocularly so that optic fibers were not inadvertently recorded. In these cases, the electrodes were advanced into the tectum until the amplitude of the SNPs or spontaneous tectal unit activity was maximal, which typically occurred at 200-300 $\mu \mathrm{m}$. In those cases in which the eyes were not injected with TTX such as in the photostimulation study, light flashes and visual stimuli were used to confirm that the electrodes were located in the primary retinoceptive layer of the tectum. Because unit recording could potentially be from either optic fibers or tectal cells in the latter cases, only SNPs were analyzed. The signal from each electrode was first amplified $(100 \times)$ and filtered by a Grass P-15 AC differential preamplifier. Filter settings were typically $3.0 \mathrm{~Hz}$ for the low-frequency cutoff and $10 \mathrm{kHz}$ for the highfrequency cutoff. For studies in which SNPs and units were simultaneously recorded, the signal was split into two channels. One channel that was amplified without further filtering provided field records. The second channel was high-pass filtered at $600 \mathrm{~Hz}$ and was used for unit recording. Similar recording techniques have been described for other systems (Thompson et al., 1969; Verzeano, 1970). The recording system was tested by electrically stimulating the optic nerve to induce field potentials. The waveforms of these field potentials were indistinguishable from those recorded by the conventional glass electrode and DC amplification methods (Schmidt and Edwards, 1983; Langdon and Freeman, 1987; van Deusen and Meyer, 1990). All recordings were digitized at $50 \mathrm{kHz}$ and stored using a DataWave acquisition system running on a personal computer. Analysis was done off-line using DataWave software (see below).

Multiunit records were obtained by using threshold detection on the high-pass channel to record time-stamped events. The threshold was set at $\sim 33 \%$ above the estimated noise level. This threshold was kept throughout the experiment that typically included sequential recordings from each tectum using the same electrode. Waveforms of the detected units were visually displayed and monitored during the experiments. On average, two to three distinct waveforms were seen, each of which exhibited a fixed amplitude and 2-3 msec duration. All units were postsynaptic because optic activity was eliminated before recording.

Pharmacology. All drugs were applied in a similar manner. Varying amounts of $10-40 \mathrm{~mm}$ stock solutions of D,L-2-amino-5-phosphonovaleric acid (APV; Sigma) or $\beta$-hydrastine (BH; Research Biochemicals, Natick, MA) were added to BSS to give the desired final concentration in the range of $1-200 \mu \mathrm{M}$ and then perfused over the tissue through the bath line. Drug effects were seen in vitro in as rapidly as 3 min indicating that the system provided good drug access to the tectal tissue. Effects were seen in vivo over a slightly longer time course, on the order of 5-10 min. To facilitate drug penetration in vivo, a low concentration of dimethylsulfoxide (DMSO) was added to the drug-containing BSS (100 $\mu \mathrm{l}$ of DMSO per $50 \mathrm{ml}$ of BSS or $0.2 \%$ ). Drugs were washed out with normal BSS.

Analysis. Average multiunit rates in spikes per second were measured at multiple sites in both the normal and the regenerating tectum of each animal. Typically data were processed in $10 \mathrm{~min}$ blocks to produce two to three block averages for each position that were then inspected for alterations in the average rate. Any recording sites that showed large 
Spontaneous Multiunit Tectal Activity Increases During Regeneration

Figure 1. Bar graphs of the percent change in spontaneous unit activity at different times during regeneration. Change was calculated by dividing the average rate measured in the regenerating tectum by the average rate measured in the normal tectum from the same animal and expressed as the percent difference. Error bars represent the SE. In vivo data are given in the bars grouped to the left, and the pair of bars on the right represents in vitro data. An effect of time of regeneration for the in vivo recordings was found to be significant $\left({ }^{*} p=0.012\right.$, one-way ANOVA).

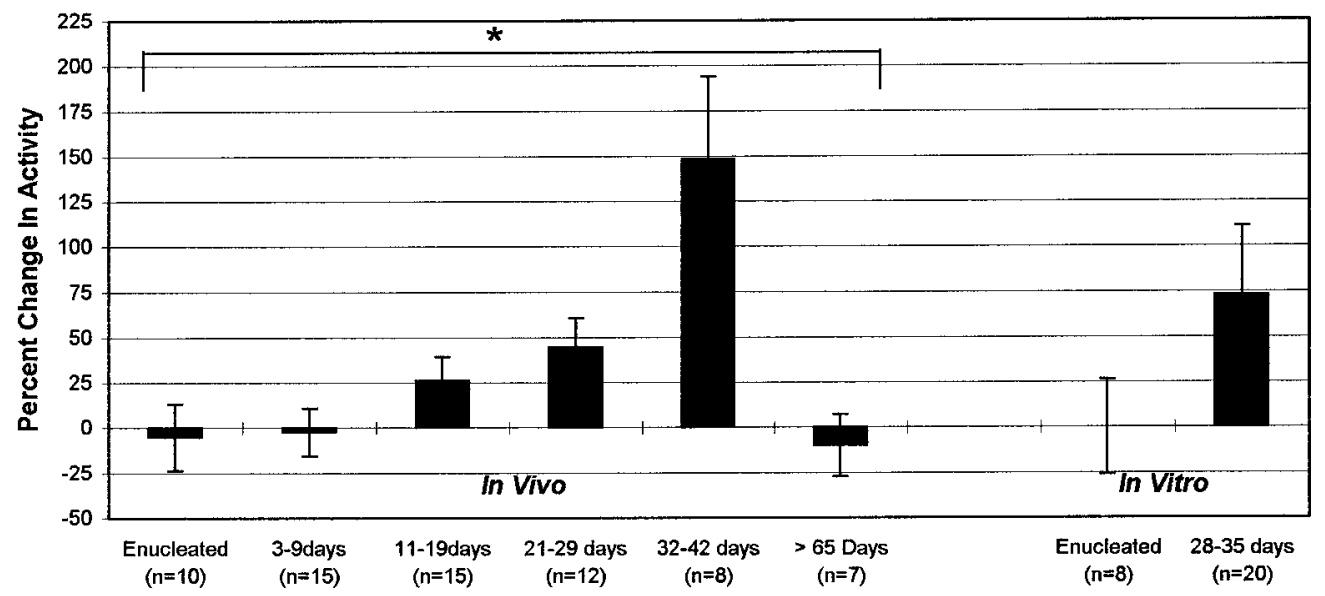

changes in the average rate between blocks were considered to be the result of unstable recordings and were not analyzed further. The blocks were then combined to yield an average rate for the given recording position, and the average rates from all positions were used to calculate the average rate for each tectum. The multiunit rates were normalized by dividing the rate calculated in the experimental tectum by the rate measured in the normal tectum from the same animal using the same electrode. A single ratio was calculated for each animal. The animals were grouped according to the time after optic nerve crush or after enucleation, and the ratios from all animals in each group were used to calculate the average for the group. Significance between the ratios from the groups was tested using a one-way ANOVA followed by ad hoc comparison of pairs using $t$ tests with a Bonferroni correction. SNP rates were calculated in the same way using $10 \mathrm{~min}$ blocks to derive average rates for each recording position and then combining these rates to calculate an average SNP frequency for each tectum. Rates were compared using one-way ANOVA and then an ad hoc $t$ test between pairs.

Amplitudes of SNPs were measured off-line using the DataWave analysis software. SNPs were recorded so that the peak of the SNP typically occurred in the center of a 120 -msec-long record. Cursors were used to define the central portion of the records in which to measure the maximal negative potential from baseline. These measures were written to a text file that was then imported into spreadsheet software for additional analysis and statistical comparison using one-way ANOVA and $t$ test analyses. Area measures were not routinely made because the variability in the waveform required, for technical reasons, manually demarcating boundaries for measurement that introduced judgment into the measure. However, area measures were made in a subset of data from 16 regenerating fish. The area was found to have a correlation coefficient with a negative height of 0.64 indicating that they are related measures.

Cross-correlation analysis has been described in detail elsewhere (Perkel et al., 1967a,b; Kirkwood, 1979; Aertsen and Gerstein, 1985). Briefly, cross-correlation analysis was performed on data in which simultaneous recordings of spontaneous multiunit activity and SNPs were made. SNP events were used as the reference events. The $300 \mathrm{msec}$ period before and after each reference event was divided into $5 \mathrm{msec}$ bins. For each bin, the spontaneous unit events or SN Ps occurring at the same electrode or at a second electrode at some distance away were counted and then plotted as a histogram. The histograms were printed out and visually inspected for central peaks and valleys.

\section{RESULTS}

\section{Time course for increased unit activity during regeneration}

Previous anatomical studies have shown that regenerating optic fibers invade the tectum at $\sim 14 \mathrm{~d}$ after optic nerve crush and form an approximately ordered retinotopic projection by $30 \mathrm{~d}$ (Schmidt et al., 1983; Stuermer and Easter, 1984; Meyer et al., 1985). Between 30 and $60 \mathrm{~d}$, activity-dependent refinement takes place during which fine retinotopic order is generated (Schmidt et al.,
1983; Meyer et al., 1985). This period will be referred to as "refinement" although some modest additional refinement occurs between 60 and $90 \mathrm{~d}$ (Meyer et al., 1985). Although a previous electrophysiological study had shown that spontaneous activity was higher than normal during refinement (Lyckman and Meyer, 1995), a time course analysis was not done to determine whether this increase was temporally associated with refinement. To determine this, we measured in vivo spontaneous unit activity in the tectum every other day at 3-29, 32-42, and 65-95 d after nerve crush. To isolate spontaneous tectal cell activity from retinal input, we gave all animals an intraocular injection of TTX 12-24 hr before recording. In an initial series, a trend toward higher activity in the regenerating tectum compared with the normal tectum of the same animal was noticed, but a considerable variation in the measured spontaneous rates was found that could be attributable to sampling bias from different electrodes. To control for this, the same electrode was used to record from multiple sites in the regenerating and normal tectum of the same animal. Activity was then expressed as a ratio of the average unit rate recorded in the regenerating tectum over that recorded in the normal tectum. The average ratios expressed as a percentage are presented in Figure 1, left group. A clear trend of increasing levels of activity during the course of regeneration was seen with a $30-50 \%$ increase in activity 11-29 d after crush and a $150 \%$ increase $32-42 \mathrm{~d}$ after crush. These increases were followed by a return to normal levels in the postrefinement period after $>65 \mathrm{~d}$ of regeneration.

Because the increased activity observed at 32-42 d subsequently returned to normal by $60 \mathrm{~d}$, we asked whether these changes were associated with the state of the innervation or simply represented changes with time after denervation. To distinguish between these, we analyzed tectal activity levels at 14$21,28-42$, and $>60 \mathrm{~d}$ after removing one eye. There was no significant difference between the average ratios for these groups ( $p=0.8655$, one-way ANOVA), so the data were pooled to produce the average ratio for enucleated tecta $(0.89 \pm 0.19)$ shown in Figure 1. Comparison of the pooled data with normal rates demonstrated no significant differences $(p=0.3844)$. To ensure that pooling did not mask any differences, we also compared the rates from the 28-42 d enucleated tecta with that from the normal tecta from those same animals. No significant differences were found ( $p=0.218$, one-tail $t$ test). Thus, regenerating 
Raw Data Examples of SNP

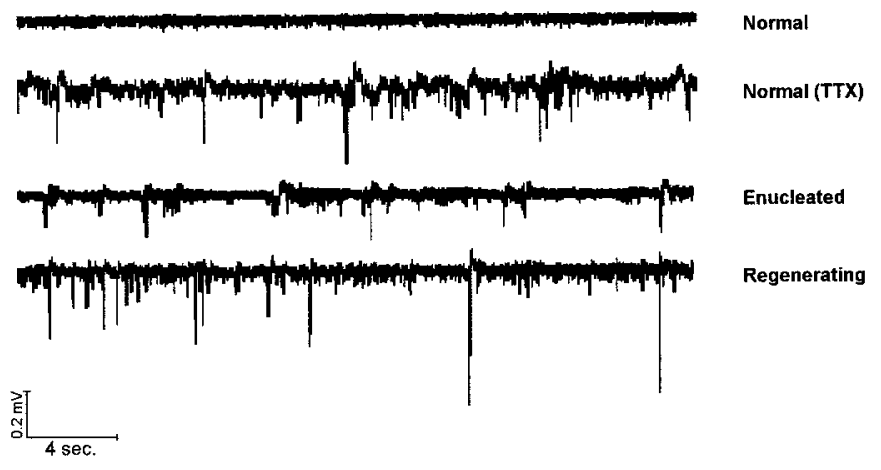

Figure 2. Examples of multiple SNPs in raw data recordings from a normal animal with no previous TTX injection (Normal), a normal animal that received an intraocular TTX injection $24 \mathrm{hr}$ before recording [Normal (TTX)], a tectum in vitro $28 \mathrm{~d}$ after enucleation (Enucleated), and a regenerating animal $35 \mathrm{~d}$ after optic nerve crush (Regenerating). Calibration: $4 \mathrm{sec}, 0.2 \mathrm{mV}$.

axons are required for the increased spontaneous (nonopticdriven) tectal activity associated with refinement.

\section{Unit activity levels within the tectum are intrinsically regulated}

To test whether the increased tectal activity during regeneration represented a change that was intrinsic to the tectum or, instead, reflected a change in the activity of nonoptic tectal inputs, we measured tectal activity in the isolated tectum in vitro. These animals did not receive previous intraocular TTX injections because this preparation isolates the tectum from all inputs other than intrinsic tectal circuits. Comparison of the ratios calculated from tecta 28-35 d after nerve crush and enucleated tecta demonstrated a $70 \%$ higher average level of activity in regenerating tecta over normal and chronically denervated tecta (Fig. 1, right pair; $p=0.022$, one-tail $t$ test).

\section{SNPs}

During the course of the above studies, we noted the occurrence of periodic, large, negative potentials in the regenerating tecta. These SNPs were single, randomly occurring, negative-going slow changes of $\sim 70-120 \mathrm{msec}$ in duration with variable amplitudes ranging from -0.15 to $-1.5 \mathrm{mV}$ (Figs. 2, 3). Occasionally a positive potential followed the negative potential, but in most cases the entire event was a monophasic negative potential. SNPs were present at all periods of regeneration but appeared to be larger and more frequent during the refinement period. They were never observed in a normally innervated tectum with normal retinal activity (Figs. 2, 3B; no TTX). Their shape and size were very similar to that of the field response to photostrobe stimulation (Fig. 3) or electrical stimulation of optic nerve (Schmidt, 1979). Like field potentials, SNPs were recordable at all depths within the tectum, and their negative amplitude was maximal in or near the stratum fibrosum et griseum superficiale of superficial tectum. In contrast to field potentials, which reverse in polarity below the SFGS (Schmidt, 1979), laminar analysis of SNPs revealed no polarity reversal (data not shown). SNPs remained negative potentials at all depths. Also, SNPs appeared to peak at 200-300 $\mu \mathrm{m}$ compared with the peak negativity for field potentials at $\sim 150-175 \mu \mathrm{m}$ (Schmidt, 1979). In the following studies, SNPs were recorded at depths of 175-250 $\mu \mathrm{m}$ that represent the deeper portion of the SFGS or the main optic innervation layer of the tectum (Meek, 1983). This depth was best for multiunit recording, and the SNPs were generally maximal at this depth.

\section{SNPs are induced by a lack of optic drive}

To determine when SNPs were occurring in regeneration, we analyzed the occurrence of SNPs at various times during regeneration. Initially we found that SNPs were seen as early as $7 \mathrm{~d}$ after injury. Because optic fibers are not likely to have reinnervated the tectum at these early times, denervation itself may be sufficient to induce SNPs. To test this more directly, we looked for SNPs in enucleated tecta and found them to be present at 7, 14 , and $28 \mathrm{~d}$ after denervation. We then considered the question of whether it was the reduced excitatory input or the deafferentation that induces SNPs. To answer this, we injected TTX into the eyes of normal fish and made in vivo recordings at various times after injection. SNPs were consistently present 12-24 hr after TTX injection (Figs. 2, 3). We then performed experiments in which TTX was injected while simultaneously recording from the tectum. Within 10 min after TTX injection, tectal activity dropped to $<10 \%$ of pre-TTX levels (Table 1 ). This time course was closely comparable with the loss of visually evoked activity that followed intraocular TTX injection in control animals. In these controls, photoflash stimuli were used to monitor the onset of TTX blockade, and visually evoked activity was found to be greatly reduced at $10 \mathrm{~min}$ and undetectable by $15-20 \mathrm{~min}$. Over the next hour, spontaneous tectal activity slowly increased, and small SNPs began to appear along with the return of spontaneous unit activity that now occurred in bursts (data not shown). Thus, induction of SNPs does not require denervation of the tectum. This induction by TTX was not mimicked by complete darkness indicating that the loss of spontaneous activity in optic fibers is the critical event for generating SNPs. It is also noteworthy that the onset of SNPs was significantly longer than the loss of spontaneous activity caused by TTX. This implies that SNPs are not an acute result of the loss of spontaneous activity in optic fibers but represent a delayed physiological response to this loss.

\section{Focal photostimulation suppresses SNPs}

The lack of SNP events in normal tecta and their appearance after silencing of optic afferents suggested that optic input might be preventing the production of SNPs. To determine whether, indeed, optic input suppresses SNPs, we attempted to modulate the occurrence of SNPs by applying a visual stimulus to several groups of animals in which SNPs were occurring and stimulation of input was possible. Focal photostimuli were presented in the visual field corresponding to one electrode. A second electrode positioned outside of the receptive field was used as a simultaneous control for global changes in activity. The strobe was flashed at one of three frequencies, $1.0,0.5$, or $0.2 \mathrm{~Hz}$, and the effects on SNP frequency were recorded. We applied this protocol to three different experimental groups expressing SNPs: normal fish recovering from TTX blockade (TTX-normal), regenerating fish 28-42 d after nerve crush (refinement fish), and regenerating fish $>65 \mathrm{~d}$ after injury (postrefinement fish). To induce SNP events in normal animals, TTX was injected intraocularly 3-5 d before recording. The TTX blockade was partially relieved after 3-5 d so that there was some visual input with residual SNPs. The other two groups normally exhibited SNP activity and were not injected with TTX.

The results are summarized in Figure 4 as the fractional decrease in the frequency of SNPs during visual stimulation. The 

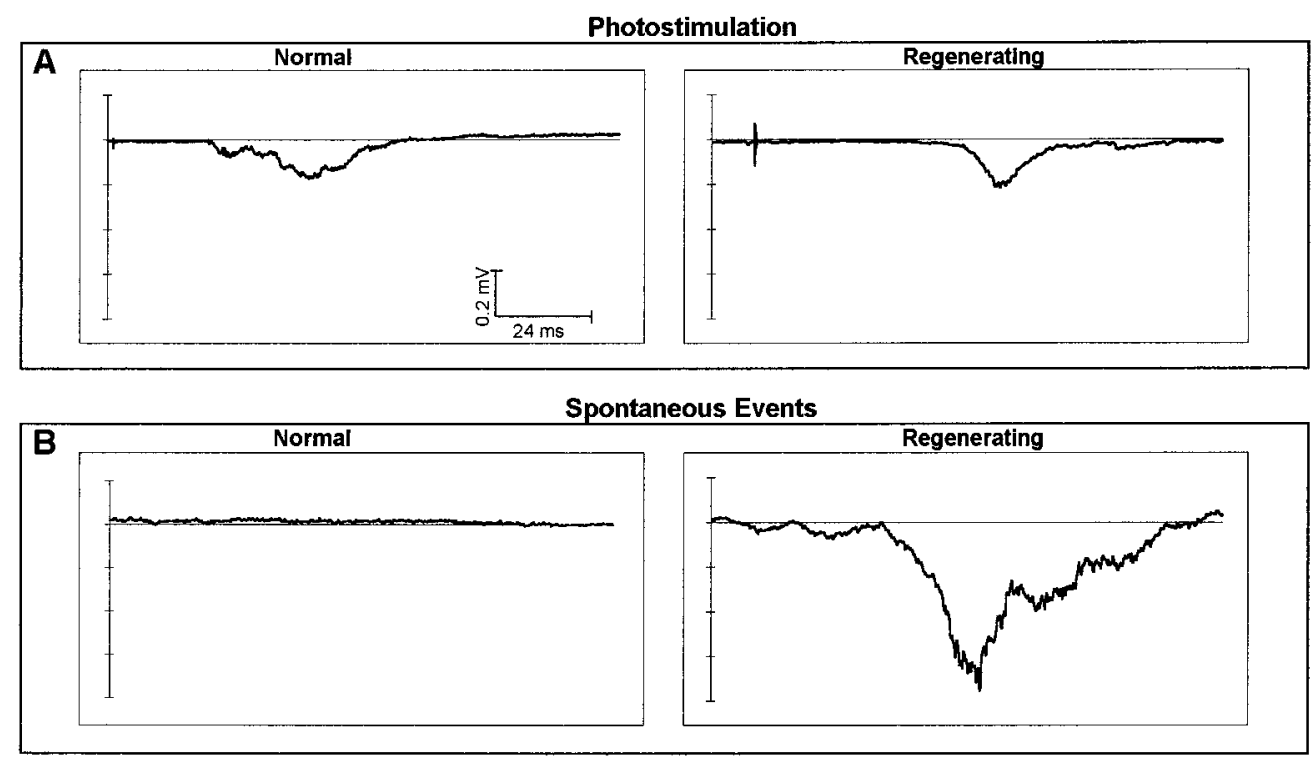

Figure 3. Examples of individual SNPs and photoevoked responses recorded in vivo. A, Photostimulus responses for normal (left) and 32-dregenerating (right) tecta. $B$, Recordings of spontaneous slow-wave activity from a normal animal (left) showing no SNPs and a 25-dregenerating animal (right) showing an SNP. No TTX was used in either animal. $C$, SNPs recorded from a normal animal (left column) and from a regenerating animal (right column). TTX was injected in the eye $24 \mathrm{hr}$ before all recordings. Each record is $120 \mathrm{msec}$ long, and the $y$-axis calibration is 0.2 $\mathrm{mV} /$ division. The calibration in $A$ applies to all figures.
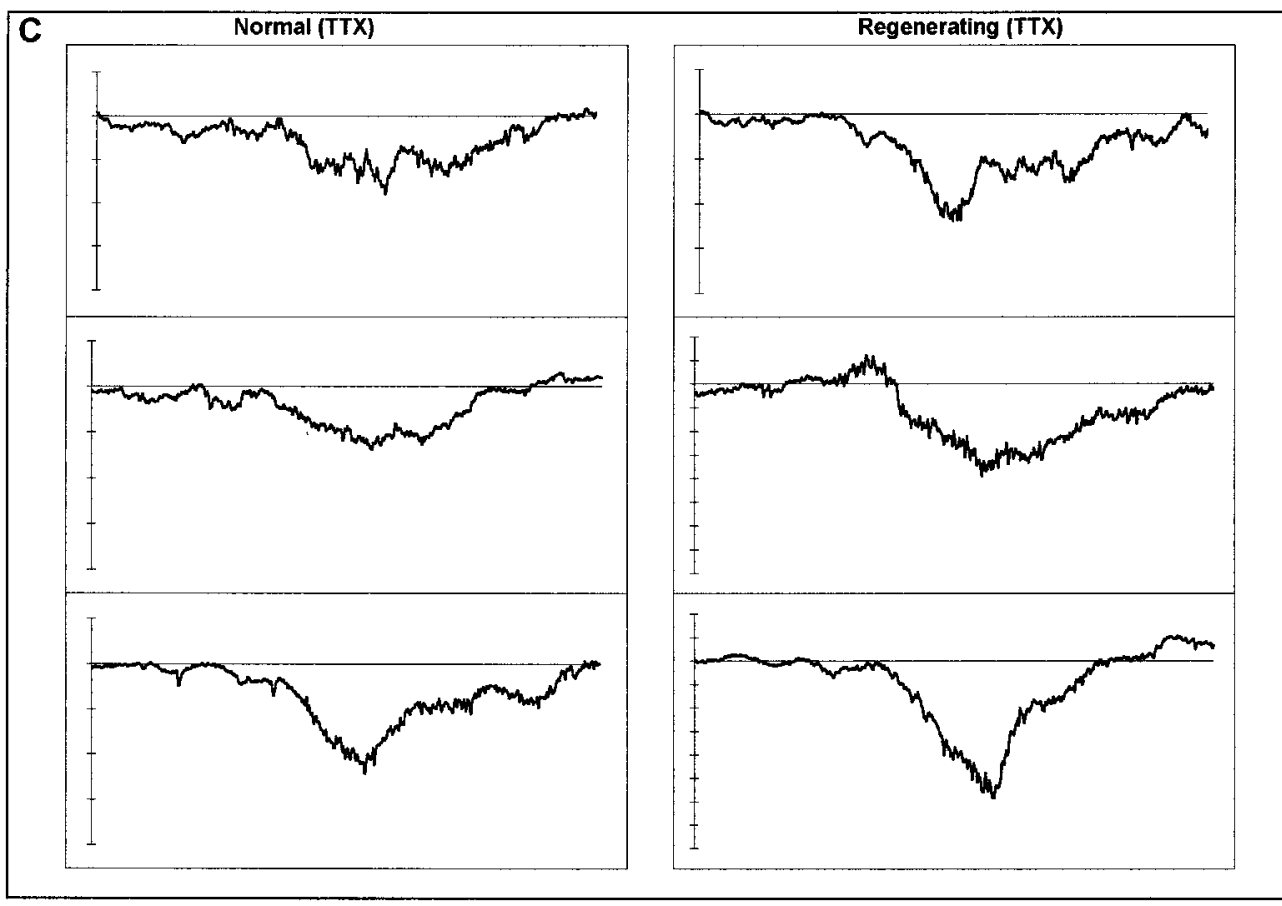

fractional decrease was calculated by dividing the frequency of SNPs that occurred during the stimulus period by the frequency during the previous nonstimulus period. For all groups, visual stimulation at $1.0 \mathrm{~Hz}$ consistently produced a suppression of SNP frequency. TTX-normal fish (Fig. $4 A$ ) demonstrated a significant ( $p<0.005$, paired $t$ test) $40 \%$ decrease in SNP frequency. Refinement fish (Fig. 4B) showed a significant 20\% suppression at $1.0 \mathrm{~Hz}(p<0.05$, paired $t$ test). Postrefinement fish (Fig. 4C) were also significantly suppressed, decreasing by $60 \%(p<0.005$, paired $t$ test). The 0.5 and $0.2 \mathrm{~Hz}$ stimuli also suppressed SNPs although these frequencies were less effective. TTX-normal fish were significantly suppressed by $20-30 \%$ (Fig. $4 A$ ). In refinement fish suppression did not reach significance. In postrefinement fish (Fig. $4 C$ ), significant suppression was seen at these lower frequencies ( $p<0.005$, one-tail $t$ test) with a trend for higher suppression at higher frequencies. The visual stimulus produced no significant change in the rate of SNPs recorded from the control electrode outside of the visual field. These results are consistent with retinal input suppressing the production of SNPs.

\section{SNPs are generated within the tectum}

Because the above experiments were done in vivo, we could not exclude the possibility that input from other brain regions was producing the SNPs in the tectum. To determine whether activity within intrinsic tectal circuits was responsible for generating the SNPs, we recorded from normal and previously denervated tecta in vitro. The eye was removed a minimum of $14 \mathrm{~d}$ before recording, so there was no chance for spontaneous release of transmitter from optic axons to generate tectal cell activity. Under these conditions, these tecta still produced SNPs (Fig. 2, Enucleated) indicating that changes intrinsic to the tectum were generating and maintaining SNP activity. Normal tecta also demonstrated 


\begin{tabular}{|c|c|c|c|c|c|}
\hline & Normal & Enucleated & $3-19 \mathrm{~d}$ & $21-42 d$ & $>65 \mathrm{~d}$ \\
\hline \multicolumn{6}{|l|}{ In vivo } \\
\hline$n$ & $102 / 51^{a}$ & $19 / 10$ & $64 / 32$ & $31 / 17$ & $22 / 11$ \\
\hline No TTX & $39.2 \pm 2.44^{b}$ & NA & NA & $6.02 \pm 0.75$ & $22.8 \pm 1.30$ \\
\hline $30 \min \mathrm{TTX}$ & $2.72 \pm 0.95$ & NA & NA & $5.96 \pm 1.04$ & $7.69 \pm 2.29$ \\
\hline 24 hr TTX & $7.76 \pm 0.63$ & $8.14 \pm 0.79^{c}$ & $7.75 \pm 0.71$ & $9.62 \pm 1.14^{*}$ & $7.37 \pm 1.12$ \\
\hline \multicolumn{6}{|l|}{ In vitro } \\
\hline$n$ & $20 / 18$ & $8 / 5$ & NA & $20 / 18$ & NA \\
\hline No TTX & $5.85 \pm 1.21$ & $6.64 \pm 1.73$ & NA & $7.00 \pm 1.62$ & NA \\
\hline
\end{tabular}

\footnotetext{
${ }^{a}$ Number of recordings per number of tecta.

${ }^{b}$ Rates are given as mean $\pm \mathrm{SE}$.

${ }^{c}$ The one normal eye in each animal was injected with TTX $24 \mathrm{hr}$ before recording.

*Significantly different from the average rate of normal tecta of same animals $(p<0.02)$.
}

SNPs in vitro presumably as a result of the loss of optic activity associated with cutting the optic nerve and removing the tecta (see below).

\section{SNPs are correlated with local synchronous activity}

While recording SNPs, we noticed that they appeared to be concurrent with bursts of unit activity that could be heard on the audiomonitor. To determine whether these were, in fact, correlated, we split the signal from each electrode into a low-passfiltered signal optimal for SNP records and a high-pass-filtered signal optimal for unit records. As shown in the raw data examples in Figure 5, SNPs were synchronous with unit discharges recorded at the same electrode. To measure the degree of synchrony, a cross-correlation was computed between the SNPs, as the reference, and unit activity. As shown in Figures 6, $A$ and $B$, and 7, $A$ and $B$, unit activity was invariably tightly correlated to SNPs recorded by the same electrode as indicated by a large central peak in the correlogram. No major temporal shifts in the peak relative to the reference were seen indicating that the unit bursts coincided with the SNPs, although some of the peaks were slightly skewed to the right (Figs. $6 A, 7 B$ ). This skewing might reflect the temporal nature of the bursts, which exhibited a relatively fast onset followed by a slow offset (Fig. 5).

To determine how local this correlation was, recordings were made with two electrodes spaced $<500$ or $>800 \mu \mathrm{m}$ apart. Correlograms were computed between the two electrodes using the SNPs recorded at one electrode as the reference for either the multiunit or SNP activity recorded from the other electrode. Representative cross-correlogram examples are given in Figures 6 and 7. For recordings at $<500 \mu \mathrm{m}$ apart, in all 16 cases there was strong correlation of SNPs to SNPs and SNPs to multiunit activity as demonstrated by the large central peak in the correlograms (Fig. 6C-F). However, this strong correlation was lost if the electrodes were placed $800 \mu \mathrm{m}$ or more apart (Fig. $7 C-F$ ). In some, 7 of 14 normal and 9 of 11 regenerating fish, there were brief episodes lasting 3-5 sec, when SNPs occurred synchronously between electrodes that were $>1000 \mu \mathrm{m}$ apart. However, these episodes were too infrequent to generate significant peaks in the cross-correlograms although small central tendencies were sometimes seen (Fig. 7E). No shifts in the peaks relative to the reference were noted for any of the cross-correlograms, suggesting that the events are not propagated consistently in any one particular direction. There was also no evidence of a temporal shift or broad-based peaks in the correlograms computed between distant electrodes using SNP recordings and binning ranges of \pm 1 min (data not shown), ruling out slowly propagated events. Finally, no differences in the correlation patterns were seen between normal tecta with optic fibers silenced with TTX and regenerating tecta.

\section{The frequency and amplitude of SNPs are increased during refinement}

Because SNPs correlate with spontaneous tectal activity, which increases during refinement, and SNPs are suppressed by optic activity, one might expect that SNPs would be expressed during regeneration and regress as synaptic connections are restored. To examine this, we measured the rate of SNPs at various times during the course of regeneration. SNPs were measured without altering retinal activity with TTX or visual stimuli. As shown in Figure $8 A$, SNPs progressively increased to their highest frequency during refinement at $30-45 \mathrm{~d}$ and then progressively decreased at later times so that they were essentially absent in late regeneration. Although optic fibers were active in these recordings, the SNPs were not being driven by optic fibers because acute TTX injection did not alter the occurrence of SNPs (compare average rates at $30 \mathrm{~min}$ after TTX for the normal and 21-42 d groups in Table 1 and see the following). Thus, SNPs are occurring during refinement and regress after refinement.

Because we had found that spontaneous tectal activity recorded 12-24 hr after intraocular TTX also peaked during refinement (see above), we wondered whether this might also be true for SNPs. To examine this, both eyes were injected with TTX, and after 12-24 hr, SNPs were recorded in both the regenerating and normal tecta. Rates were expressed as the mean number of SNPs per second. Again, higher mean rates were observed in regenerating tecta, and this peaked during refinement (Fig. 8B). Relative amplitude also tended to increase during regeneration reaching statistical significance during refinement (Fig. 8C). Although relative amplitude did not decrease immediately after refinement, the frequency did decrease implying there were fewer SNPs after refinement. To confirm this, average amplitude and frequency were selectively calculated for SNPs that were $0.2 \mathrm{mV}$ or larger. As shown in Figure 8D, the mean frequency of these large SNPs again progressively increased, peaking during refinement $(p<$ 0.0005 , one-tail $t$ test), and then decreased in late regeneration. The average relative amplitude was increased by comparable magnitudes in both the refinement and postrefinement $(p<0.01$ and $p<0.003$, respectively, one-tail $t$ test) group. Thus, refinement is associated with the occurrence of a greater number of 
Focal Photo-stimulation Suppresses SNPs
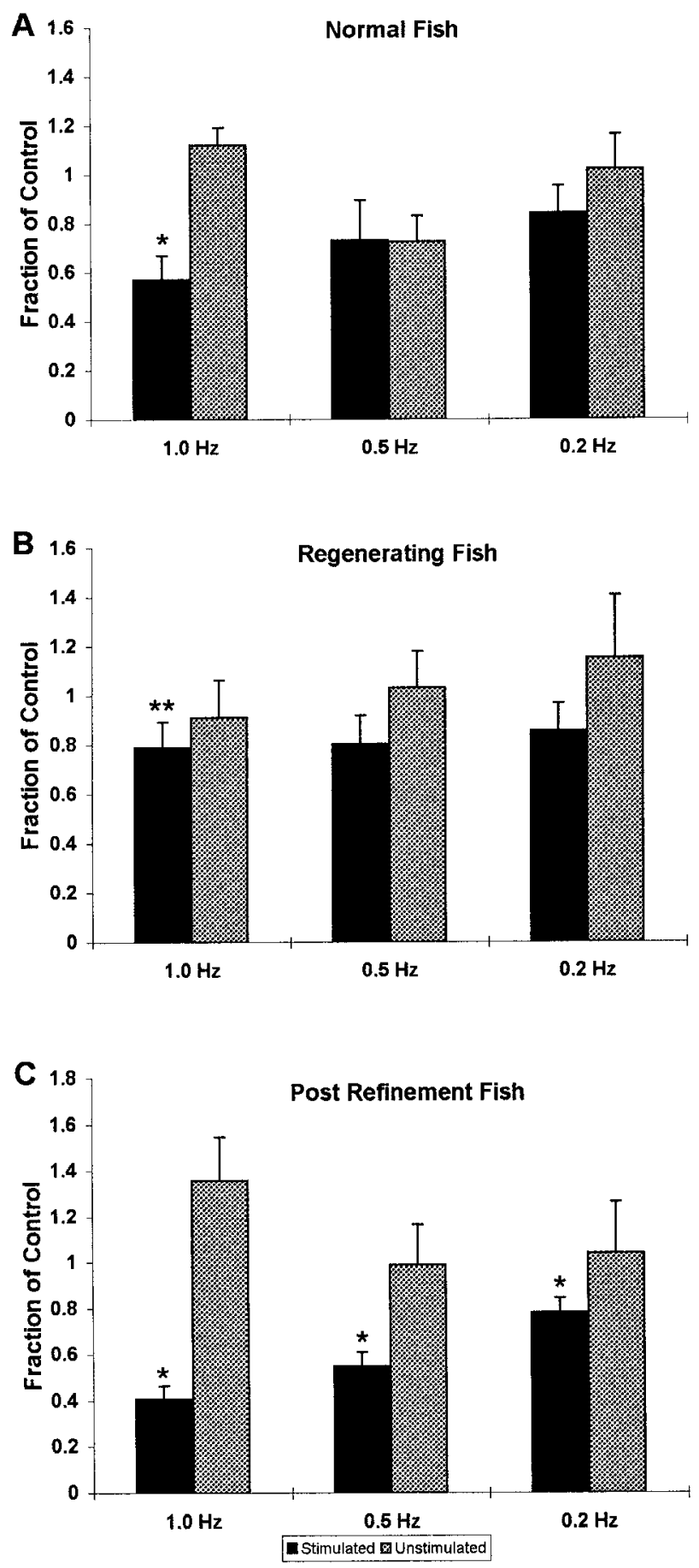

Figure 4. Histograms showing suppressive effect of three different frequencies of focal photostimulation on the rate of SNPs. The frequency of SNPs during the stimulus was expressed as a fraction of that recorded during a control period. Black bars were recordings corresponding to the receptive field, and gray bars were outside the receptive field. $A$, Normal fish that received an intraocular injection of TTX 3-5 d before recording. SNP frequency was significantly suppressed by photostimulation in the receptive field at $1 \mathrm{~Hz}\left({ }^{*} p<0.005\right.$, paired $t$ test $)$. $B$. Fish $28-42 \mathrm{~d}$ after optic nerve crush without TTX. SNP frequency was similarly suppressed by $1 \mathrm{~Hz}$ stimulation ${ }^{* *} p<0.05$, paired $t$ test). $C$, Fish $67-83 \mathrm{~d}$ after optic nerve crush without TTX. SNP frequency was significantly suppressed at all frequencies with a trend for increased suppression at higher frequencies $\left({ }^{*} p<0.005\right.$, paired $t$ test $)$.
SNPs are Tightly correlated to Local Unit Activity

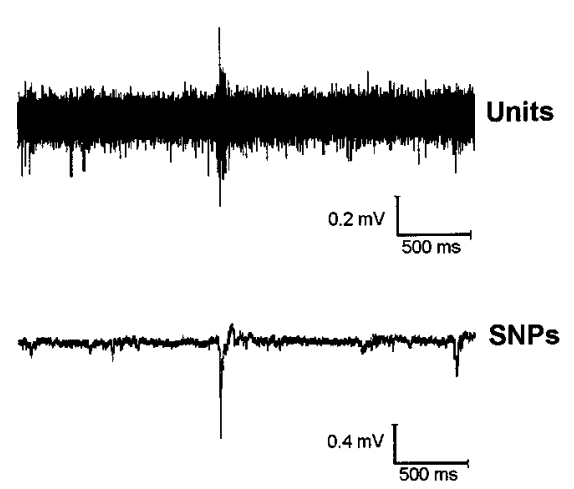

Figure 5. Five second records of units and SNPs simultaneously recorded by the same electrode showing that SNPs are coincident with unit bursts. Recording is from a fish $42 \mathrm{~d}$ after optic nerve crush that had received an intraocular injection of TTX $30 \mathrm{~min}$ before recording. The amplitude calibration represents $0.02 \mathrm{mV}$ for the unit record and $0.4 \mathrm{mV}$ for the SNP record, and the time calibration is $500 \mathrm{msec}$ for both.

larger SNPs, which can be attributed to intrinsic changes in the tectum.

\section{Blockade of the NMDA subtype of glutamate receptors decreases the rate of SNPs}

We found previously that blockade of the NMDA subtype of glutamate receptors with the specific antagonist APV dramatically suppresses spontaneous unit activity in the tectum in a dose-dependent manner (Kolls and Meyer, 1995). Because SNPs are tightly correlated with underlying unit activity, we asked whether SNPs would also be suppressed by APV. As shown in Figure 9, in vivo application of $100 \mu \mathrm{M}$ APV suppressed SNPs by $\sim 80 \%$ in TTX-blocked normal projections and by $\sim 70 \%$ in regenerating projections (TTX) at 28-42 d after nerve crush. APV also decreased SNPs in regenerating tecta of fish that had not received previous intraocular TTX by an average of $60 \%$. The decrease in SNP frequency was significant for each group $(p<$ 0.001 , paired $t$ test); however, there was no significant difference between normal and regenerating tecta $(p=0.885$, one-way ANOVA). These results are consistent with the possibility that SNPs are generated by local unit activity and are not simply correlated with it.

\section{$\mathrm{GABA}_{\mathrm{A}}$ receptor blockade increases the frequency of both SNPs and unit activity}

If suppressing spontaneous activity decreases SNPs, then increasing activity might be expected to increase SNPs if they are associated with tectal activity. Antagonizing $\mathrm{GABA}_{\mathrm{A}}$ receptors might normally be expected to increase tectal activity and increase SNPs. However, during development of the hippocampus, pyramidal cells exhibit spontaneous periodic bursting termed giant depolarizing potentials (GDPs) that are produced, in part, by GABA acting as an excitatory transmitter at $\mathrm{GABA}_{\mathrm{A}}$ receptors (Ben-Ari et al., 1989; Cherubini et al., 1991). Consequently, $\mathrm{GABA}_{\mathrm{A}}$ antagonists suppress GDPs (Ben-Ari et al., 1989). If a similar mechanism were operating in goldfish, antagonizing $\mathrm{GABA}_{\mathrm{A}}$ receptors might actually suppress SNPs. To resolve this, we examined the effects of the $\mathrm{GABA}_{\mathrm{A}}$ receptor antagonist $\mathrm{BH}$ on unit activity and on the frequency of SNPs in both normal and regenerating fish. $\mathrm{BH}$ at $10 \mu \mathrm{M}$ significantly increased the unit 
Normal (TTX)

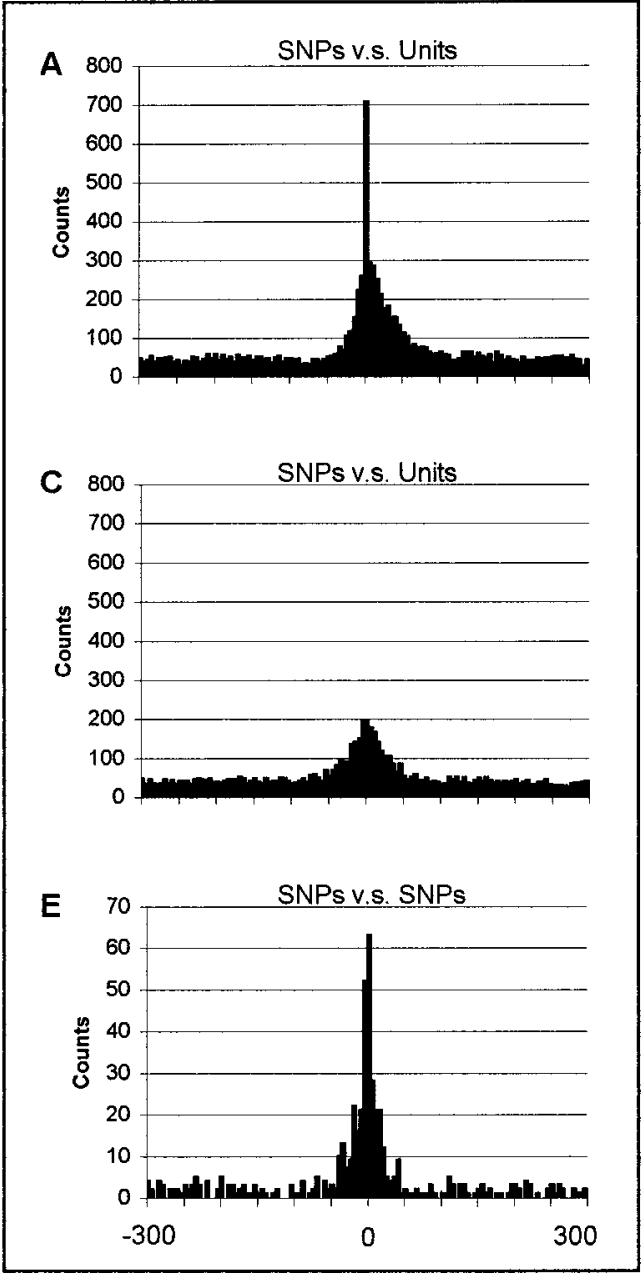

Regenerating

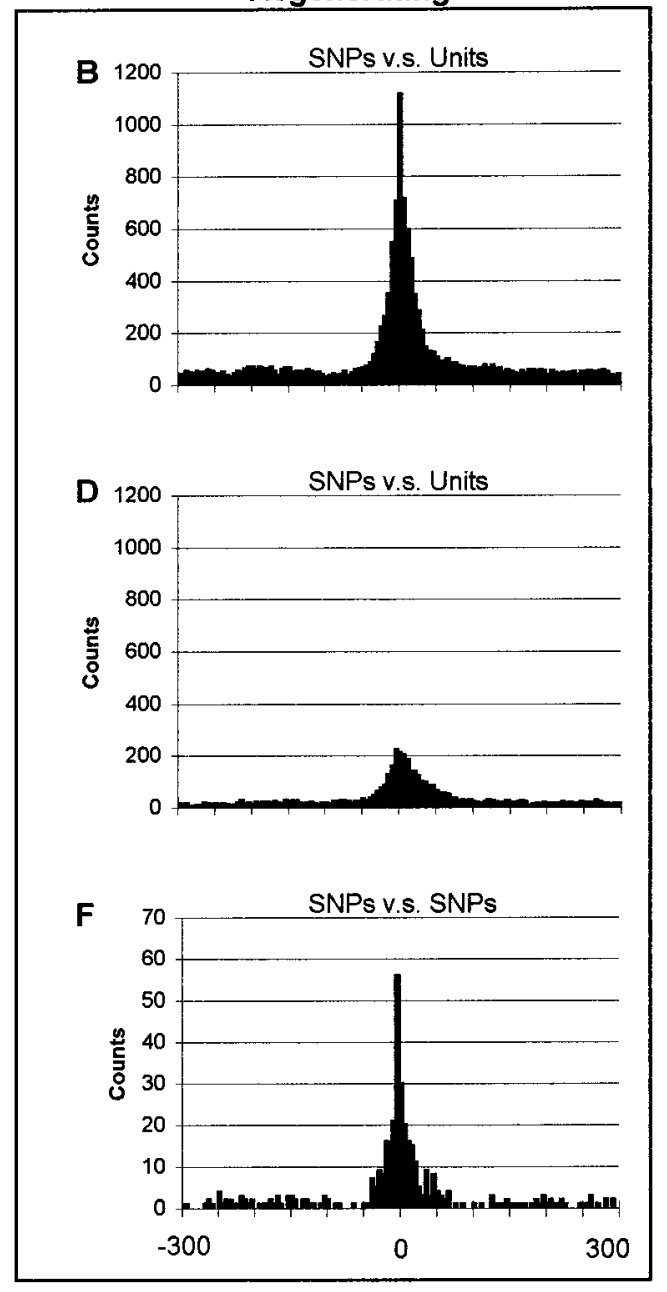

Figure 6. Cross-correlograms computed between SNPs as the reference and neighboring SNPs or unit activity. Correlograms were plotted in bins of 5 msec over a range of \pm 300 msec relative to the reference SNP. $A, C, E$, From a normal fish with a previous intraocular injection of TTX. $B, D, F$, From a fish $35 \mathrm{~d}$ after optic nerve crush and with previous intraocular TTX. $A, B$, Cross-correlogram between SNPs and the unit activity recorded by the same electrode showing a large central peak. $C, D$, Crosscorrelogram between SNPs and the unit activity recorded by a second electrode $150 \mu \mathrm{m}$ away also producing a large central peak. $E, F$, Crosscorrelation of SNPs to SNPs recorded with two different electrodes $150 \mu \mathrm{m}$ apart also producing a large central peak. v.s., Versus. activity levels in all animal groups ( $p<0.01$, paired $t$ test). The effects of BH on multiunit activity are summarized (see Fig. 11B). $\mathrm{BH}$ also increased SNPs in all animals. It significantly increased the rate of SNPs in a normal animal in which SNPs were induced by previous intraocular TTX ( $p<0.01$, paired $t$ test) as shown in Figure 10 and summarized in Figure $11 A$. It also induced SNPs in normal animals without intraocular TTX, which normally never produce SNPs (Fig. 10). In regenerating fish, BH generated a 30-fold increase in SNPs ( $p<0.01$, paired $t$ test), and this was significantly larger than that seen in normal fish $(p<0.02$, one-tail $t$ test). Thus, increased activity is associated with an increase in SNPs, and $\mathrm{GABA}_{\mathrm{A}}$ receptors mediate inhibition during regeneration.

\section{DISCUSSION}

\section{Spontaneous tectal activity greatly increases during refinement}

We measured the activity of tectal neurons in the primary optic innervation layer of tectum at various times after crushing the nerve. Activity was "spontaneous" in that it was not driven by optic fibers that were absent or silenced by TTX 12-24 hr before and activity occurred in acutely isolated tecta in vitro. Spontaneous activity measured relative to that of the normal tectum (TTX silenced) was found to increase progressively with time after nerve crush by $24 \%$ at $11-19 \mathrm{~d}$ and $45 \%$ at $21-29 \mathrm{~d}$, peaking at $150 \%$ of normal during activity-dependent refinement at $32-42 \mathrm{~d}$ and returning to normal levels at $>65 \mathrm{~d}$. The increases between 11 and 29 d were comparable with those reported previously for this period (Lyckman and Meyer, 1995). The large increase at 32-42 d was not simply the result of denervation because it was not induced by removing the eye for the equivalent period. Because activity was only modestly increased at 21-29 d when large numbers of regenerating fibers invade the tectum (Stuermer and Easter, 1984; Meyer et al., 1985) and because activity was normal at late stages of regeneration, the dramatic increase at 32-42 d appears specifically associated with the peak period of activity-dependent refinement. This suggests that elevated spontaneous activity in the tectum may be an important component of refinement.

A caveat to these studies is that it is possible the electrical characteristics of the tectal milieu were altered during regeneration in a way that altered the number or types of neurons that were sampled in the recordings. This could come about, for example, by a reaction of glial cells leading to a change in extracellular space. Although this cannot be rigorously excluded, it seems unlikely that the findings can be entirely explained in these terms. SNPs, which mirrored underlying unit activity, similarly increased during regeneration. Because SNPs were gross DC potentials and were relatively unaffected by changes in electrode position and characteristics, they should be much less sensitive to sampling bias. 
Figure 7. Cross-correlograms between SNPs as the reference and distant SNPs or unit activity. Conventions are the same as in Figure 6. $A, C$, $E$, From a normal fish with previous TTX. $B, \quad D, F, \quad$ From a 35-dregenerating fish with previous TTX. $A, B$, Cross-correlogram of SNPs to the unit activity recorded by the same electrode producing a large central peak. $C, D$, Cross-correlation between SNPs and the unit activity recorded by a second electrode $1000 \mu \mathrm{m}$ away producing a flat cross-correlogram. $E, F$, Cross-correlation between SNPs at one electrode and SNPs recorded by a second electrode $1000 \mu \mathrm{m}$ away producing a flat cross-correlogram.
Normal (TTX)

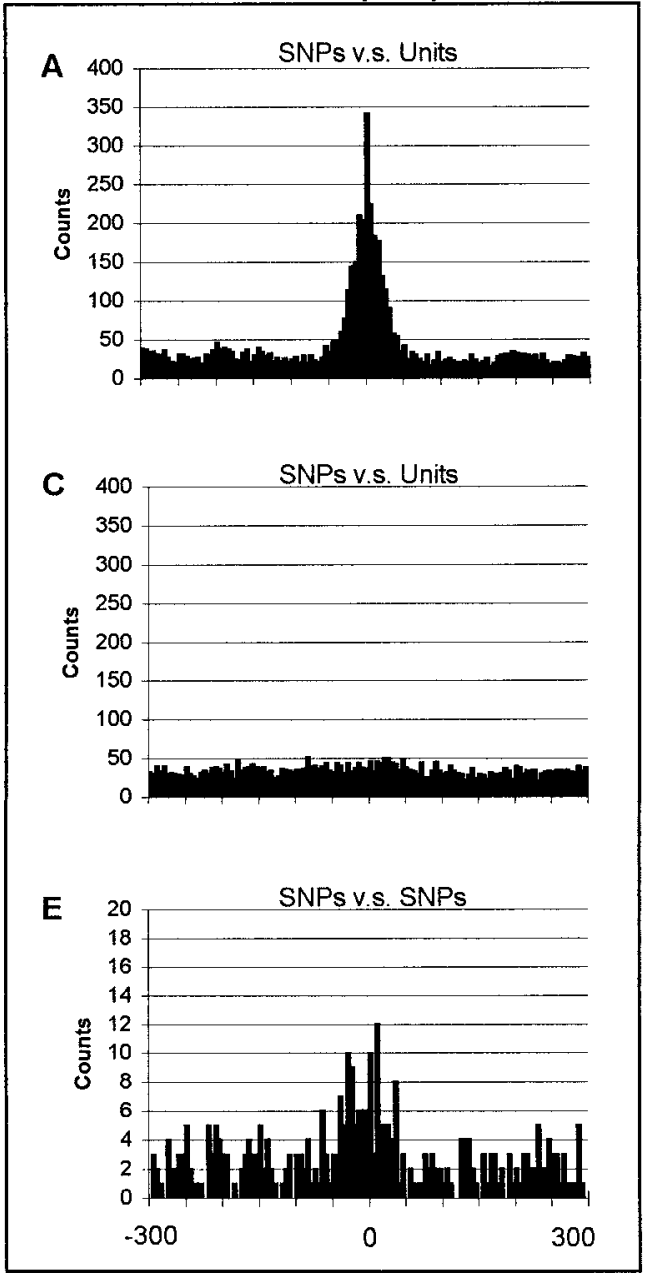

Regenerating

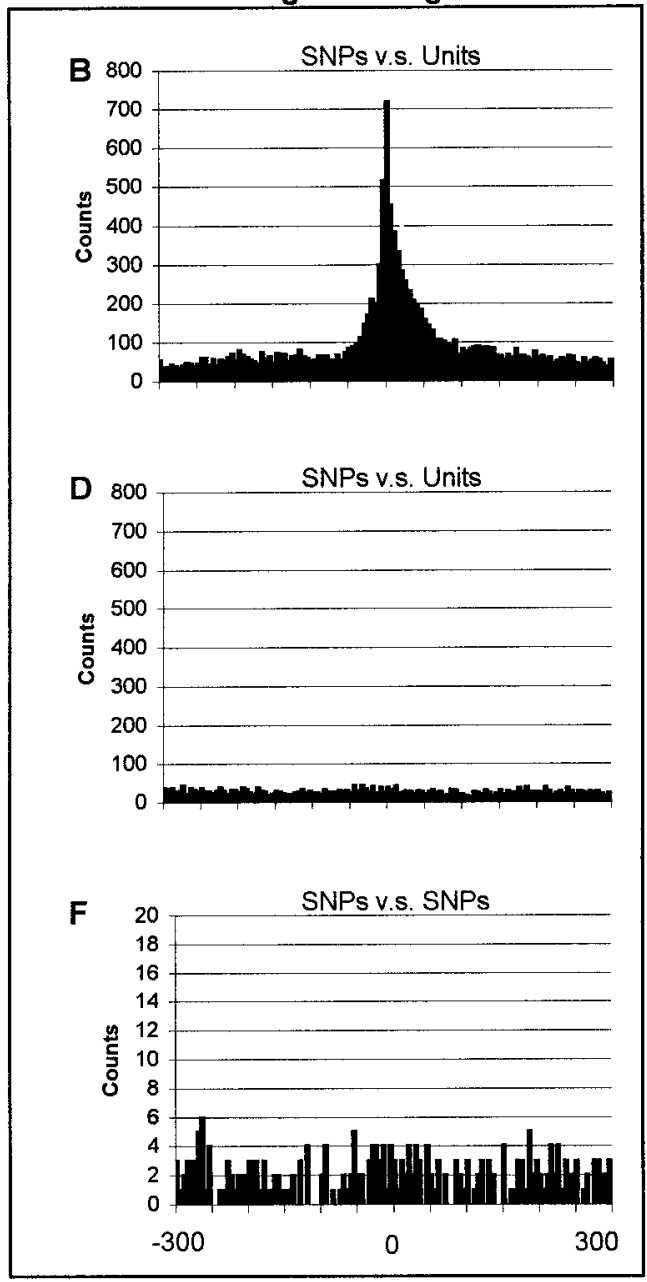

How regenerating optic fibers elevate spontaneous (nonopticdriven) tectal activity is not known. A trophic interaction between optic fibers and tectal cells is one possibility (Bonhoeffer, 1996). Optic impulse activity is another. Although optic impulse activity was eliminated by TTX for the measurements, it is possible it nevertheless exerted a conditioning effect and chronically increased tectal activity (and SNPs). Previous studies on goldfish (Northmore, 1987; Oh and Northmore, 1998) found that although optic activity was initially suppressed after optic axotomy, both spontaneous and evoked activity progressively increased, peaking at $\sim 40 \mathrm{~d}$ of regeneration at approximately the time when postsynaptic tectal responses measured in torus longitudinalis recovered (Northmore, 1989a,b). ON-OFF center units actually reached supranormal levels at $40 \mathrm{~d}$ (Oh and Northmore, 1998). However, there is a complication in this comparison. These previous studies severed optic fibers closer to the tectum (tract vs our intraorbit surgery) and maintained fish at a higher temperature $\left(25^{\circ} \mathrm{C}\right.$ vs our $\left.19-20^{\circ} \mathrm{C}\right)$. It is likely that regeneration proceeded faster in these previous studies, so it is possible that their $40 \mathrm{~d}$ corresponds to our $60 \mathrm{~d}$. This raises the alternative interpretation that the return to normal levels of spontaneous tectal activity is caused by the recovery of activity in optic fibers and the reestablishment of transmission. This will need to be resolved in future studies.

\section{SNPS}

While studying unit activity, we observed spontaneous negative slow potentials in the tectum during regeneration. SNPs were negative monophasic potentials of $70-120 \mathrm{msec}$ duration and variable size, typically -0.15 to $-0.3 \mathrm{mV}$, but some were as large as $-1.5 \mathrm{mV}$. They occurred in regenerating tecta with no apparent periodicity at an average frequency of $\sim 0.3-0.6 \mathrm{~Hz}$. These were spontaneous in that they were not driven by optic fibers, which were absent or silenced by TTX, and were observed in acutely isolated tecta. They were not seen in a normally innervated tectum.

It may seem surprising that SNPs have not been characterized previously considering the number of electrophysiological studies on regenerating goldfish. The only report was an incidental observation made in a study of tectal units (Meyer and Brink, 1988). A possible reason is that SNPs are two orders of magnitude longer than action potentials and would have been filtered out by the bandpass setting typically used in unit recordings. Although SNPs would not have been filtered out in DC recordings of evoked potentials, they might have been easily missed because SNPs are typically less than a tenth the size of an evoked potential.

SNPs were closely associated with the spontaneous episodic bursting in clusters of neighboring tectal neurons. Cross- 
A SNP Frequency Changes During Regeneration (No TTX)

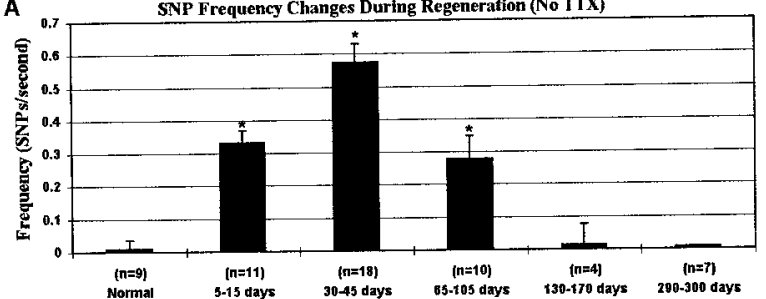

B

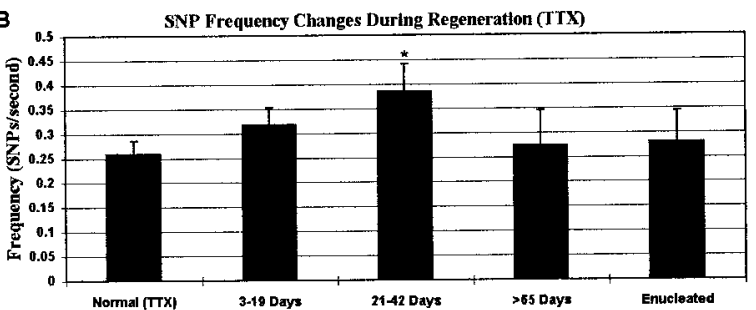

C

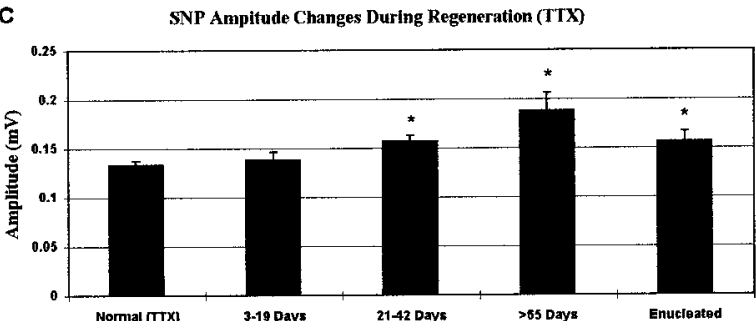

D Changes in Mean Amplitude and Frequency of SNPs $\geq 0.2 \mathrm{mV}$ (TTX)

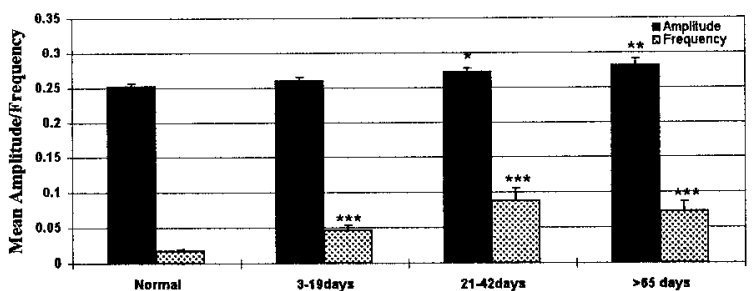

Figure 8. Histograms showing changes in SNP amplitude and frequency during regeneration. $A$, The mean number of SNPs per second $( \pm \mathrm{SE}$ ) in normal tecta and in tecta at different times of regeneration. No TTX was used for the recordings. The maximal rate of SNPs was observed at 30-45 $\mathrm{d}$ after crush ( $p<0.05$, one-tail $t$ test vs 5-15 d and vs 65-105 d), and all regenerating tecta had significantly increased rates except those $>130 \mathrm{~d}$ after crush ( ${ }^{*} p<0.02$, one-tail $t$ test). $B$, SNP frequency recorded in similar fish but with intraocular TTX injection 12-24 hr before recording. Rates tended to increase during regeneration and were significantly elevated at $21-42 \mathrm{~d}$ after nerve crush $\left({ }^{*} p<0.02, t\right.$ test $) . C$, Histogram of the average amplitude of SNPs $( \pm \mathrm{SE})$. Amplitude was significantly larger in the 21-42 d, $>65 \mathrm{~d}$, and enucleation groups [ ${ }^{*} p<0.003$, one-tail $t$ test vs Normal $(T T X)]$. D, Histogram of the average frequency (gray bars) and amplitude (black bars) of SNPs with an amplitude of $0.2 \mathrm{mV}$ or greater. The frequency was significantly greater during regeneration $\left({ }^{*} p<0.01\right.$; $* * p<0.005$, one-tail $t$ test) and peaked during refinement. Amplitude similarly increased $(* * * p<0.001$, one-tail $t$ test). $B-D$, For each group, the number of recordings/number of tecta: normal, 90/45; 3-19 d, 46/23; 21-42 d, 26/13; >65 d, 8/4; and enucleated, 14/7.

correlation analysis demonstrated that SNPs were strongly correlated with unit activity recorded at the same tectal position. The large peak in the unit correlogram was not only temporally coincident with the SNP, but also the width of the correlation peak was comparable with the average duration of SNPs. Thus, SNPs and unit activity were temporally covariant. The pronounced peak in the unit autocorrelation function (data not
APV Suppresses SNP Frequency

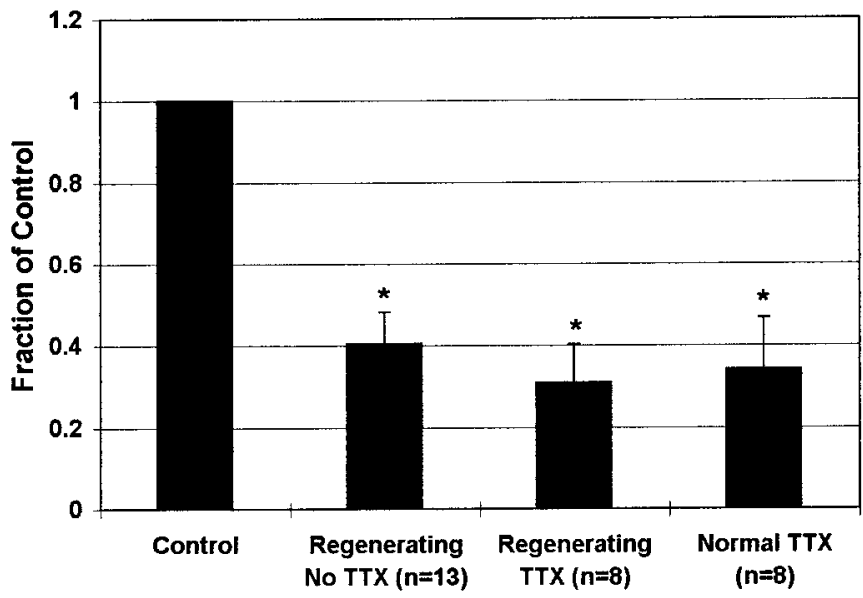

Figure 9. Histogram showing suppressive effect of APV on the frequency of SNPs in normal and regenerating fish. Frequency was expressed as the ratio of the rate of SNPs recorded before and during application of $100 \mu \mathrm{M}$ APV and plotted as the mean \pm SE for each group. APV significantly suppressed SNP frequency ( ${ }^{*} p<0.001$, paired $t$ test), and no significant differences were found between the three groups $(p=$ 0.885 , ANOVA).

shown) indicated that unit activity tended to occur in bursts as seen in previous studies (Meyer and Brink, 1988; Lyckman and Meyer, 1995). SNPs and unit activity were also spatially covariant. The correlation between SNPs and unit activity decreased with distance so that it was relatively weak over 300-500 $\mu \mathrm{m}$ and was essentially absent at distances $>500 \mu \mathrm{m}$. The same spatial dependence was found in the correlations of SNPs to SNPs and of units to units. Two previous studies had also shown that spontaneous tectal activity is locally correlated (Meyer and Brink, 1988; Lyckman and Meyer, 1995). Pharmacological analysis also showed parallel effects on both spontaneous activity and SNPs. APV reduced or eliminated spontaneous activity levels and similarly reduced or eliminated SNPs. Increasing spontaneous activity with a $\mathrm{GABA}_{\mathrm{A}}$ antagonist increased the number and amplitude of SNPs. These observations indicate that SNPs may either represent the summed synaptic and spike currents generated by the periodic bursting of neighboring tectal neurons or reflect synaptic currents that produce the tectal bursting. In any event, SNPs are clearly associated with local neuronal impulses as has been shown for other DC potentials (Verzeano and Calma, 1954) and can be considered an index of correlated bursting.

\section{Regulation of SNPs}

SNPs are induced by a loss of optic drive. They were observed under all conditions that result in a loss of impulse activity at optic synapses (eye removal, nerve crush, and intraocular TTX). Because they were seen whether optic synapses were absent (eye removal) or present (late regeneration, normal fish with intraocular TTX, and isolated tectum), it is the loss of impulse activity, not loss of synapses, that is critical. Also, total darkness did not induce SNPs, so it is the loss of spontaneous rather than visually induced activity. The delayed onset of SNPs in normal fish by 40-50 min after TTX-induced silencing of the retina indicates that SNPs result not as an acute response to the loss of input but from a physiological change in tectum that follows the loss of input. 


\section{Raw Data Examples of $\beta$-Hydrastine on SNPs}

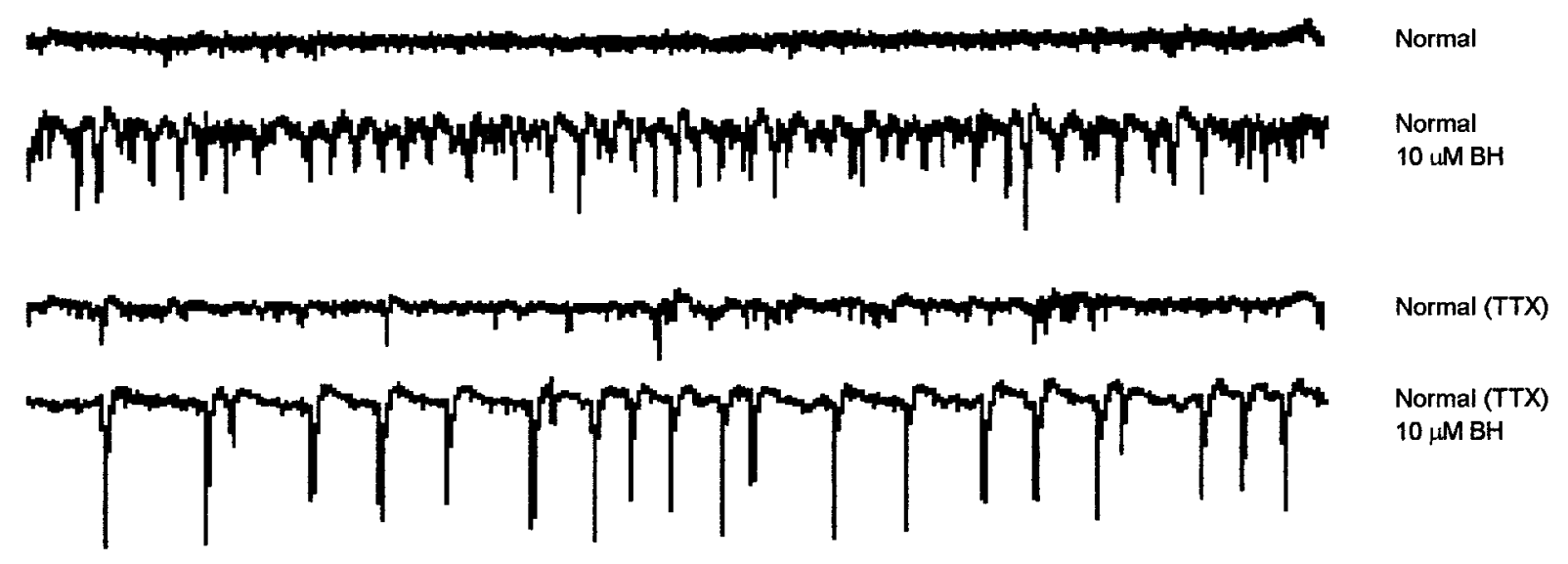

$2 \mathrm{mV} \mathrm{T}_{4 \text { seconds }}$

Figure 10. Raw data examples showing the effect of $10 \mu \mathrm{M} \mathrm{BH}$ on SNP production. Top pair of traces, From a normal tectum without any intraocular TTX before (top) and after (bottom) BH administration. SNPs were only seen with BH. Bottom pair of traces, From a normal fish with intraocular TTX injection $24 \mathrm{hr}$ before recording. Before BH (top), some SNPs were observed. After BH (bottom), the number of SNPs increased. Each trace is a 30 sec segment of raw data.

If SNPs are regulated by spontaneous optic activity, one might expect that they would regress after nerve regeneration. SNPs did progressively decrease after refinement so few were seen after $130 \mathrm{~d}$. The decrease, however, took much longer than that for the reestablishment of synaptic connections that are at normal numbers by 1 month (Murray and Edwards, 1982; Hayes and Meyer, 1989). This might result from a lack of retinotopic convergence in early regeneration, which would make it difficult for normal retinal activity to drive tectal neurons. This could still allow synchronized input such as with stroboscopic stimulation to suppress SNPs as was found. However, the occurrence of SNPs in fish at 2-4 month is surprising because most refinement has occurred by this time (Schmidt and Edwards, 1983; Meyer et al., 1985). This may mean that some critical features of the projection may require a longer time for restoration. Some anatomical refinement is detectable between 2 and 3 months (Meyer et al., 1985), the receptive field size in the tectum and torus longitudinalis requires $80-100 \mathrm{~d}$ to return to normal (Northmore, 1989a,b), behavioral recovery of high-spatial frequency sensitivity is delayed by several months (Northmore and Celenza, 1992), and myelination remains subnormal for as long as 8 months (Murray and Edwards, 1982; Hayes and Meyer, 1989).

SNPs also appear to be modulated by changes within the tectum that are associated with the presence of regenerating fibers. The frequency of SNPs progressively increased during regeneration, peaking during refinement. This increase was not driven by optic activity because it was seen when optic activity was acutely eliminated by intraocular TTX. These changes are similar to those observed for spontaneous unit activity in the tectum and likely reflect a common cause (see above). The temporal coincidence of these changes with the period of refinement suggests that they may have functional significance for refinement.

\section{Possible role for SNPs in refinement}

Spontaneous, local, episodic activity has been seen during development in several systems including retina, hippocampus, and
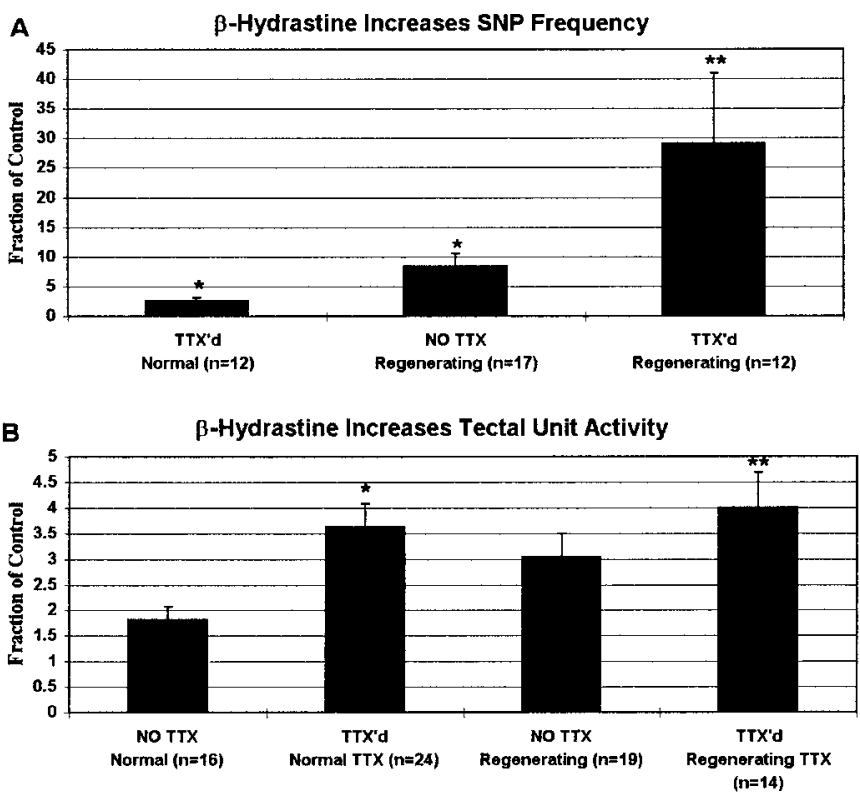

Figure 11. Histograms of the effect of $10 \mu \mathrm{M} \beta$-hydrastine on SNP frequency and spontaneous unit activity. Ratios were calculated as described in Figure 9. A, Histogram of SNP frequency. Frequency was significantly increased in normal fish with previous intraocular TTX injection (TTX'd Normal) and in regenerating fish with (TTX'd Regenerating) and without (NO TTX Regenerating) previous intraocular TTX $\left({ }^{*} p<0.01\right.$, paired $t$ test $)$. The increase in regenerating animals with previous TTX was significantly greater than the increase seen in the non-TTX-regenerating group $\left({ }^{* *} p<0.02\right.$, one-tail $t$ test). $B$, Histogram summary of $\mathrm{BH}$ effects on the rates of spontaneous unit activity. Rates were significantly increased in all groups $(p<0.01$, paired $t$ test). Rates were twofold higher in normal fish with no previous intraocular TTX injection (NO TTX Normal) and $>3.5$-fold higher in normal tecta with intraocular TTX ( $T T X^{\prime} d$ Normal $\left.T T X\right)$. These differed significantly from each other $\left({ }^{*} p<0.02\right.$, one-tail $t$ test). Similarly, during regeneration, fish with intraocular TTX (TTX'd Regenerating $T T X)$ showed a significantly larger increase in unit rate $\left({ }^{* *} p<0.04\right.$, one-tail $t$ test). 
cortex. Two kinds of instructive functions have been proposed for this activity: patterning of efferents and the assembly of local circuits. The activity produced by retinal waves is thought to provide the driving force for patterning the optic projection to the lateral geniculate nucleus and possibly the cortex (Meister et al., 1991; Wong et al., 1993). Spontaneous episodic activity in the developing mammalian cortex (Yuste et al., 1995; Katz and Shatz, 1996; Kandler and Katz, 1998), hippocampus (Ben-Ari et al., 1997; Leinekugel et al., 1997), and turtle retina (Sernagor and Grzywacz, 1995) has been postulated to contribute to the formation of local circuitry. Neither of these functions seems to be likely for SNPs in the adult goldfish because tectal efferents and local circuits are mature and apparently do not change during nerve regeneration (Murray and Edwards, 1982; Hayes and Meyer, 1989).

We suggest that SNPs may reflect an additional role for spontaneous locally correlated activity: target activity that facilitates the assembly of afferent projections. SNPs may serve to boost sensitivity to optic input during nerve regeneration. Although the normal number of optic synapses is reestablished by 1 month after nerve crush (Hayes and Meyer, 1989), they lack fine retinotopic order (Meyer et al., 1985). The lack of convergence from neighboring retinal ganglion cells would be expected to make it difficult for locally correlated activity in the ganglion cells to produce impulse activity de novo in tectal cells. However, weak optic inputs might be able to trigger the onset of an SNP. This would produce a correlation between presynaptic and postsynaptic activity that could then drive a Hebbian process of refinement. Because SNPs involve the correlated bursting of many neighboring tectal cells, this could effectively produce correlated pre- and postsynaptic activity over a multicellular domain of tectum. This would greatly increase the detection range for correlated activity and could explain why ocular dominance columns comprise multicellular domains of tectum (or cortex). In short, SNPs may lower the threshold for activation and create multicellular targets for refinement.

\section{REFERENCES}

Aertsen AM, Gerstein GL (1985) Evaluation of neuronal connectivity: sensitivity of cross-correlation. Brain Res 340:341-354.

Arnett D, Spraker TE (1981) Cross-correlation analysis of the maintained discharge of rabbit retinal ganglion cells. J Physiol (Lond) 317:29-47.

Arnett DW (1978) Statistical dependence between neighboring retinal ganglion cells in goldfish. Exp Brain Res 32:49-53.

Ben-Ari Y, Cherubini E, Corradetti R, Gaiarsa JL (1989) Giant synaptic potentials in immature rat CA3 hippocampal neurones. J Physiol (Lond) 416:303-325.

Ben-Ari Y, Khazipov R, Leinekugel X, Caillard O, Gaiarsa JL (1997) GABAA, NMDA and AMPA receptors: a developmentally regulated "menage a trois." Trends Neurosci 20:523-529.

Bonhoeffer T (1996) Neurotrophins and activity-dependent development of the neocortex. Curr Opin Neurobiol 6:119-126.

Cherubini E, Gaiarsa JL, Ben-Ari Y (1991) GABA: an excitatory transmitter in early postnatal life. Trends Neurosci 14:515-519.

Hayes WP, Meyer RL (1989) Normal numbers of retinotectal synapses during the activity-sensitive period of optic regeneration in goldfish: HRP-EM evidence implicating synapse rearrangement and collateral elimination during map refinement. J Neurosci 9:1400-1413.

Kandler K, Katz LC (1998) Coordination of neuronal activity in developing visual cortex by gap junction-mediated biochemical communication. J Neurosci 18:1419-1427.

Katz LC, Shatz CJ (1996) Synaptic activity and the construction of cortical circuits. Science 274:1133-1138.

Kirkwood PA (1979) On the use and interpretation of cross-correlations measurements in the mammalian central nervous system. J Neurosci Methods 1:107-132.
Kolls BJ, Meyer RL (1995) Effects of the NMDA receptor antagonist AP-5 on spontaneous activity in goldfish optic tectum. Soc Neurosci Abstr 21:816.

Langdon RB, Freeman JA (1987) Pharmacology of retinotectal transmission in the goldfish: effects of nicotinic ligands, strychnine, and kynurenic acid. J Neurosci 7:760-773.

Leinekugel X, Medina I, Khalilov I, Ben-Ari Y, Khazipov R (1997) $\mathrm{Ca} 2+$ oscillations mediated by the synergistic excitatory actions of GABA(A) and NMDA receptors in the neonatal hippocampus. Neuron 18:243-255.

Lyckman AW, Meyer RL (1995) Spontaneous bursting and long-lived local correlation in normal and denervated tectum of goldfish. J Neurobiol 26:109-118.

Maffei L, Galli-Resta L (1990) Correlation in the discharges of neighboring rat retinal ganglion cells during prenatal life. Proc Natl Acad Sci USA 87:2861-2864.

Mastronarde DN (1983) Correlated firing of cat retinal ganglion cells. I. Spontaneously active inputs to $\mathrm{X}$ - and Y-cells. J Neurophysiol 49:303-324.

Meek J (1983) Functional anatomy of the tectum mesencephali of the goldfish. An explorative analysis of the functional implications of the laminar structural organization of the tectum. Brain Res 287:247-297.

Meister M, Wong RO, Baylor DA, Shatz CJ (1991) Synchronous bursts of action potentials in ganglion cells of the developing mammalian retina. Science 252:939-943.

Meyer RL (1982) Tetrodotoxin blocks the formation of ocular dominance columns in goldfish. Science 218:589-591.

Meyer RL, Brink DL (1988) Locally correlated activity in the goldfish tectum in the absence of optic innervation. Brain Res 469:25-36.

Meyer RL, Sakurai K, Schauwecker E (1985) Topography of regenerating optic fibers in goldfish traced with local wheat germ injections into retina: evidence for discontinuous microtopography in the retinotectal projection. J Comp Neurol 239:27-43.

Murray M, Edwards MA (1982) A quantitative study of the reinnervation of the goldfish optic tectum following optic nerve crush. J Comp Neurol 209:363-373.

Northmore D (1987) Neural activity in the regenerating optic nerve of the goldfish. J Physiol (Lond) 391:299-312.

Northmore D (1989a) Quantitative electrophysiological studies of regenerating visuotopic maps in goldfish. I. Early recovery of dimming sensitivity in tectum and torus longitudinalis. Neuroscience 32:739-747.

Northmore D (1989b) Quantitative electrophysiological studies of regenerating visuotopic maps in goldfish. II. Delayed recovery of sensitivity to small light flashes. Neuroscience 32:749-757.

Northmore D, Celenza M (1992) Recovery of contrast sensitivity during optic nerve regeneration in fish. Exp Neurol 115:69-72.

Oh D-J, Northmore D (1998) Functional properties of retinal ganglion cells during optic nerve regeneration in the goldfish. Vis Neurosci 15:1145-1155.

Perkel DH, Gerstein GL, Moore GP (1967a) Neuronal spike trains and stochastic point processes. I. The single spike train. Biophys J 7:391-418.

Perkel DH, Gerstein GL, Moore GP (1967b) Neuronal spike trains and stochastic point processes. II. Simultaneous spike trains. Biophys J $7: 419-440$.

Schmidt JT (1979) The laminar organization of optic nerve fibers in the tectum of goldfish. Proc R Soc Lond [Biol] 205:287-306.

Schmidt JT, Edwards DL (1983) Activity sharpens the map during the regeneration of the retinotectal projection in goldfish. Brain Res 269:29-39.

Schmidt JT, Tieman SB (1985) Eye-specific segregation of optic afferents in mammals, fish, and frogs: the role of activity. Cell Mol Neurobiol 5:5-34.

Schmidt JT, Edwards DL, Stuermer C (1983) The re-establishment of synaptic transmission by regenerating optic axons in goldfish: time course and effects of blocking activity by intraocular injection of tetrodotoxin. Brain Res 269:15-27.

Sernagor E, Grzywacz NM (1995) Emergence of complex receptive field properties of ganglion cells in the developing turtle retina. J Neurophysiol 73:1355-1364.

Shatz CJ (1990) Impulse activity and the patterning of connections during CNS development. Neuron 5:745-756. 
Shatz CJ (1994) Viktor Hamburger Award review. Role for spontaneous neural activity in the patterning of connections between retina and LGN during visual system development. Int J Dev Neurosci 12:531-546.

Stuermer CA, Easter Jr SS (1984) A comparison of the normal and regenerated retinotectal pathways of goldfish. J Comp Neurol 223:57-76.

Teyler TJ, Lewis D, Shashoua VE (1981) Neurophysiological and biochemical properties of the goldfish optic tectum maintained in vitro. Brain Res Bull 7:45-56.

Thompson RF, Bettinger LA, Birch H, Groves PM (1969) Comparison of evoked gross and unit responses in association cortex of waking cat. Electroencephalogr Clin Neurophysiol 27:146-151.

van Deusen EB, Meyer RL (1990) Pharmacologic evidence for NMDA,
$\mathrm{APB}$ and kainate/quisqualate retinotectal transmission in the isolated whole tectum of goldfish. Brain Res 536:86-96.

Verzeano M (1970) Evoked responses and network dynamics. In: The neural control of behavior (Whalen RE, Thompson RF, Verzeano M, Weinberger NM, eds), pp 27-54. New York: Academic.

Verzeano M, Calma I (1954) Unit activity in spindle bursts. J Neurophysiol 17:417-428.

Wong RO, Meister M, Shatz CJ (1993) Transient period of correlated bursting activity during development of the mammalian retina. Neuron 11:923-938.

Yuste R, Nelson DA, Rubin WW, Katz LC (1995) Neuronal domains in developing neocortex: mechanisms of coactivation. Neuron 14: $7-17$. 